\title{
Have ecological niches been conserved in evolutionary time for South Asian River Dolphins?
}

\author{
Anu Rai ${ }^{1}$ \\ ${ }^{1}$ The Thin Page Pvt. Ltd.
}

September 22, 2020

\begin{abstract}
The niches of species that are geographically separated can either be conserved or diverge. This dynamic has been studied over time through Species Distribution Modeling and quantification of niche metrics. Here I have conducted this study for South Asian Dolphins. The Ganges River Dolphin and the Indus Dolphins are considered sub-species but there has been debate on this classification. The niche overlap was found to be very low meaning Indus Dolphin which most likely separated through the process of drainage capture has diverged from its original niche. The niche equivalency test also showed that there is a niche divergence is statistically significant. These dolphins could well be two separate species given their difference in niches but further study especially genetic studies are needed to affirm this. But the study highlights deviations from niche conservatism for the taxa due to significant niche shifts.
\end{abstract}

\section{Have ecological niches been conserved in evolutionary time for South Asian River Dolphins?}

Anu Rai

The Thin Page Pvt. Ltd.

https://orcid.org/0000-0002-8778-9571

raianu191@gmail.com

\begin{abstract}
The niches of species that are geographically separated can either be conserved or diverge. This dynamic has been studied over time through Species Distribution Modeling and quantification of niche metrics. Here I have conducted this study for South Asian Dolphins. The Ganges River Dolphin and the Indus Dolphins are considered sub-species but there has been debate on this classification. The niche overlap was found to be very low meaning Indus Dolphin which most likely separated through the process of drainage capture has diverged from its original niche. The niche equivalency test also showed that there is a niche divergence is statistically significant. These dolphins could well be two separate species given their difference in niches but further study especially genetic studies are needed to affirm this. But the study highlights deviations from niche conservatism for the taxa due to significant niche shifts.
\end{abstract}

\section{Keywords}

South Asian Dolphins, Species Distribution Modeling, Niche overlap, Niche equivalence

\section{Introduction}

As species are separated geographically their ecological niches can be either be conserved or diverge (Wang et al. , 2017). During separation, competing species preferentially occupy habitats and microsites which bears a close resemblance with their previous habitat. This promotes stabilizing selection and is predicted to lead to 
niche conservatism (Webb et al. , 2002). The phenotypic plasticity on the other hand allows species to adjust to heterogeneous environment. Either case can result speciation with ecological conservatism restricting the gene flow between incipient due to geographical isolation (Peterson et al. , 1999) and divergence inducing reproductive isolation as a by-product of adaptation (Rundle and Nosil, 2005a). The failure to adapt to novel environmental condition when ancestral distributional ranges shift and break up results in vicariant speciation in niche conservatism (Wiens, 2004b; Shepard and Burbrink, 2008). In divergence, phenotypic traits through phenotypic plasticity (Price et al. , 2003) and genetic mechanisms (Rundle and Nosil, 2005b) are induced leading to ecological differences being secondarily accumulated among lineages.

The niche conservatism suggests that ecological differences accumulate after the speciation event (Peterson et al. , 1999) whereas niche divergence suggests locally divergent evolutionary responses by populations, result in divergent environmental tolerances because of selective pressures across the landscape (Parmesan, 2006). There is a widespread regard that closely related species are ecologically similar leading to assumption that niche conservatism exist by default (Losos, 2008). In a way, niches are always somewhat conserved there are no sister pairs one occurring in tropical rainforest and the other in deep sea vents (Wiens and Graham, 2005). However, niche conservatism is not ubiquitous (Rato et al. , 2015; Wellenreuther et al. , 2012; Raxworthy et al. , 2007) and there is a need to examine this on a case by case basis.

This dynamic has been studied over time through Species Distribution Modeling (SDM) and the quantification of niche similarities between or within species (Warren et al. , 2008a; Broennimann et al. , 2012; Warren et al. , 2010; Muscarella et al. , 2014; Heiblet al. , 2018). SDM studies also aid in defining species delimitation (Rissler and Apodaca, 2007; Raxworthy et al. , 2007). The ecological niche modeling estimates the potential geographical distributions of species based on environmental variables. Whether there is overlap in species niches helps to understand niche conservatism or divergence among taxa.

In the present study, I use recently developed methods for SDM and calculated if the niche overlap persist for South Asian River dolphins. The detection of niche conservatism has been made through niche equivalency (whether native and non-native niches are indistinguishable) (Warren et al. , 2008a) which prior were only inferred through underlying statistical and conceptual assumptions (Strubbe et al. , 2013). This study also helps in shedding light on some aspect of species delimitation but will overall concentrates on the aspect of niche study of the South Asian River dolphins.

The South Asian River dolphins are split into two subspecies namely Ganges River Dolphin (Platanista gangetica gangetica) and Indus Dolphin (Platanista gangetica minor). The former is found in the GangesBrahmaputra-Meghna (GBM) and Karnaphuli-Sangu (KS) river system and the later in the Indus river system. It has been theorized that the Indus dolphin diverted to Indus through the process of drainage capture some 550,000 years ago (Braulik et al. , 2015). Have the species conserved their niche or not is an important topic of study. This lack of clarity can impair scientific conservation management.

Morphologically the key difference between the two dolphins has been difference in tail length. Of nearly the species of same body length, the length of tail was shorter in GRD than ID (for $118 \mathrm{~cm}$ body length, $6.7 \mathrm{~cm}$ shorter tail length in GRD) (Kasuya, 1972). Pilleri et al.(1982) however, recognized two species of South Asian River dolphins based on differences in the prominence of the nasal crests, caudal height of the maxillary crests, length of the lower transverse processes of the sixth and seventh cervical vertebrae, blood protein composition and free-esterified cholestrin ratio in the lipids. But the arguments were deemed unconvincing, due to examination made on small sample of adult specimens and the absence of statistical analyses (Reeves and Brownell Jr, 1989). The morphological difference is however seen which made the present classification as subspecies.

These two dolphins were long regarded as identical until Pilleri and Gihr (1971) divided them into two species ( $P$. gangetica and $P$. minor ). Kasuya (1972) reduced the two taxa to sub-species of $P$. gangetica . This treatment is followed in the IUCN Red List of Threatened species. There is a need to study whether species have conserved their niche or diverged through evolutionary time scale so that it can aid in resolving the species delimitation. Both the species are classified as Endangered with some sub-groups even being 
classified as Critically Endangered such as the sub-population in Nepal (Jnawaliet al. , 2011).

\section{Materials and methods}

Occurrence data and environment variables

The occurrence records of Ganges River Dolphin (GRD) across its entire range consisting of GBM \& KS river system which encompasses Nepal, India and Bangladesh and the Indus Dolphin (ID) in Indus river system which encompasses India and Pakistan were compiled. Occurrence locations were based on presence records compiled from studies conducted by several researchers (see supporting information SI1) and OBISSEAMAP (http://seamap.env.duke.edu/). A total of 724 occurrence records for GRD were compiled out of which 410 coordinates were used and 404 for ID out of which 304 coordinates were used. Absence points are considered valuable for SDM algorithms and model assessment techniques (Miller, 2010). Since I did not have true absence points, I generated 10,000 absence points for modeling using 'random' strategy. In this strategy, all cells of initial background are pseudo absence candidates and the choice are made at random. For GRD, two coordinates were discarded as they showed the presence in Bay of Bengal. This is a phenomenon that has been reported during monsoons (Moreno, 2003) however, for this study the area has been limited to riverine environment.

The basin boundary and river networks were obtained from HydroSHEDS (https://hydrosheds.org). The GBM basin provided by Hydrosheds has discarded the areas near the Bay of Bengal and some areas within the basin boundary which were merged to form the final GBM basin (see supporting information SI2). Since, the species is aquatic, the input layers were created with environmental variables clipped by river networks. This created the problem of NA predictor variable for some coordinates maybe because of factors such as coordinates reported in studies from shore based census or river network error. So, a $1 \mathrm{~km}$ coordinate pull was used to drag the coordinates into the nearest raster cell using nearestland function from the package SEEGOxford/seegSDM. Any points which did not fall even after this $1 \mathrm{~km}$ pull, were discarded. The coordinates so selected were again gridsampled to match the raster resolution such that there was one occurrence point per pixel.

19 bioclimatic raster layers were obtained from WorldClim version 2.1 climate data for 1970-2000 (https://worldclim.org/) along with 2 hydrological variables - hydrologically conditioned Digital Elevation Model and Flow Accumulation Model from Hydrosheds at 30-seconds spatial resolution to model potential distribution. Using all the variables might cause the problem of over-fitting due to high degrees of collinearity among predictors. To minimize this, Pearson Correlation matrix was created and variables with correlation $>0.7$ were discarded. In the end variables - BIO2, BIO3, BIO15, BIO16, Flow accumulation and hydrologically conditioned DEM were used. BIO2 or Mean Diurnal Range is the mean of monthly difference in maximum and minimum temperature, BIO3 or Isothermality is a measure of temperature seasonality, BIO15 or Precipitation Seasonality is a measure of annual range in precipitation, BIO16 or Precipitation of Wettest Quarter is the precipitation of the wettest quarter calculated per pixel, Flow accumulation defines the amount of upstream area (in number) draining into each cells and Hydrologically Conditioned DEM defines expected flow of water over the terrain.

\section{Distribution Modeling, evaluation and niche metrics}

I have used BIOMOD2 package 3.4.11 (Thuiller et al. , 2009) in RStudio Version 1.2.5033 (R Core Team, 2020) to perform ensemble modeling using a combination of five algorithms. These are Generalized Additive Models (GAMs), Surface Range Envelope (SRE), Random Forest (RF), Generalized Boosting Model and Artificial Neural Network (ANN). GAM is a regression-based algorithm that uses smoothers which are a set of polynomials for generating curves by local fitting to the subsection of data. SRE is an envelope-style method that creates arrays of values for each environmental variable at the given presence points. RF is a bagging approach classifies data into different classes based on homogeneity and generates result from classification tree. Under the Generalized Boosting Model which is a boosting method, each of the individual models possesses regression trees. ANN is a mathematical technique which makes an attempt to simulate biological neural networks and are trained by back propagation algorithm. Unlike modeling through single 
algorithm, ensemble modeling are considered to produce better accuracy (Araujo and New, 2007).

The models were selected with True Kill Statistic (TSS) evaluation metric with a threshold of 0.7. Data partitioning of $80 \%$ training dataset and $20 \%$ testing dataset was used. The entire procedure was repeated three times. Each model was evaluated by ROC (Relative Operating Characteristic) (=AUC) and TSS metrics. The AUC has a range from 0 to 1 and TSS range from -1 to 1 . As per the refined AUC scale, AUC $>0.9$ are considered excellent, $0.80<$ AUC $<0.90$ are considered good and so on (Araújo et al. , 2005) whereas the TSS score +1 indicates perfect agreement and values of zero or less indicate a performance no better than random.

Niche overlap values for the taxa were calculated using Schoener's D (Schoener, 1968) and Hellinger's I niche similarity metrics (Warrenet al. , 2008b) using the overlap function in 'dismo' package (Hijmans et al. , 2017). D and I qualitatively similar results although I metric tends to give higher values than D for any given comparison (Culumber and Tobler, 2016). The niche equivalency test was performed using 'phyloclim' package (Heibl et al. , 2018) with 99 replicates. This test asks whether the niches of the taxa under study are effectively indistinguishable (Warren et al. , 2008a). The equivalency of two niches are rejected if the niche overlap falls outside the $95 \%$ of the null hypotheses. The niche equivalency test using this package was chosen over some of the other popular methods such as use of 'ecospat' package as it uses occurrence density grids (Cola et al. , 2017). This is problematic in this case because the South Asian Dolphins do not share same geographical space and the models built would need to be projected into the species' geographical distribution elsewhere.

\section{Results}

\section{Species Distribution Modeling}

On average, for both the taxas Hydrologically Conditioned DEM had the highest contribution in model prediction. The second highest contribution was shown by BIO16 in both the models. Likewise, most of the models of both the taxas have performed well. Both the TSS and ROC score were higher for ID (ensemble score 0.91 and 0.97 respectively) than for GRD (ensemble score 0.81 and 0.94 respectively). On average, Random Forest performed best with high TSS and AUC scores whilst SRE model exhibited low TSS and AUC scores for both the models (Figure 1).

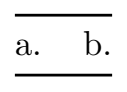

Figure 1: ROC and TSS Score of the models of a. Ganges River Dolphin and b. Indus Dolphin

The distribution modeling of both the dolphins are very much restricted to its own basin (Figure 2). Habitat of the species are mostly concentrated in the mainstem for both the species. The potentially suitable current habitat of Indus dolphin are concentrated in the south-western Indus Basin whereas the Ganges River Dolphin are concentrated in southern and central GBM basin.

The niche overlap is concentrated more in GBM basin than the Indus basin. In the Indus only the mainstem features low habitat suitability overlap (falling in 0-250 score range against an index of 0 - 1000 habitat suitability score, higher the score higher the habitat suitability prediction). The model is a projection and does not actually represent the actual distribution. The presence of dams and canals which have been catastrophic to the dolphin population has not been accounted here. 


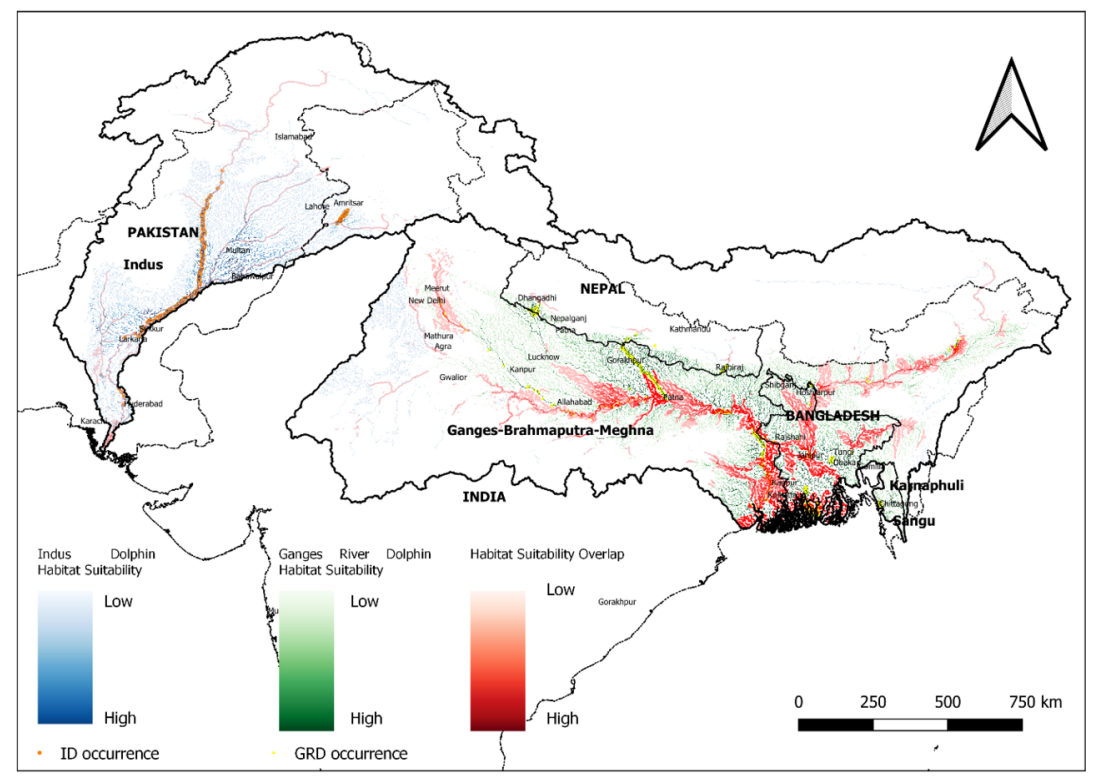

Figure 2: Predictive potential distribution map of Ganges River Dolphin and Indus Dolphin along with their habitat suitability overlap

Niche overlap and equivalence test

It was found that the niches did not overlap for the two taxa shown by very low score of Schoener's D and Hellinger's I niche similarity metrics. The score were 0.025 and 0.068 respectively representing almost nil overlap of the range of the species. Since the range do not overlap these species could most likely be treated as two separate species. But further genetic study is needed to truly ascertain the taxonomic status of the species. The Indus dolphin seems to have significantly diverged from its ecological niche as it separated from Ganges River Dolphin.

Likewise, the niche identity test has shown that the calculated niche overlap of the pair are outside the $95 \%$ confidence interval of the null hypothesis $(\mathrm{p}$-value $=0)$ (Figure 3$)$. This confirms the separation of the two species. Hence, the niches of the two species are not equivalent. 


\section{Niche identity test: GRD - ID}

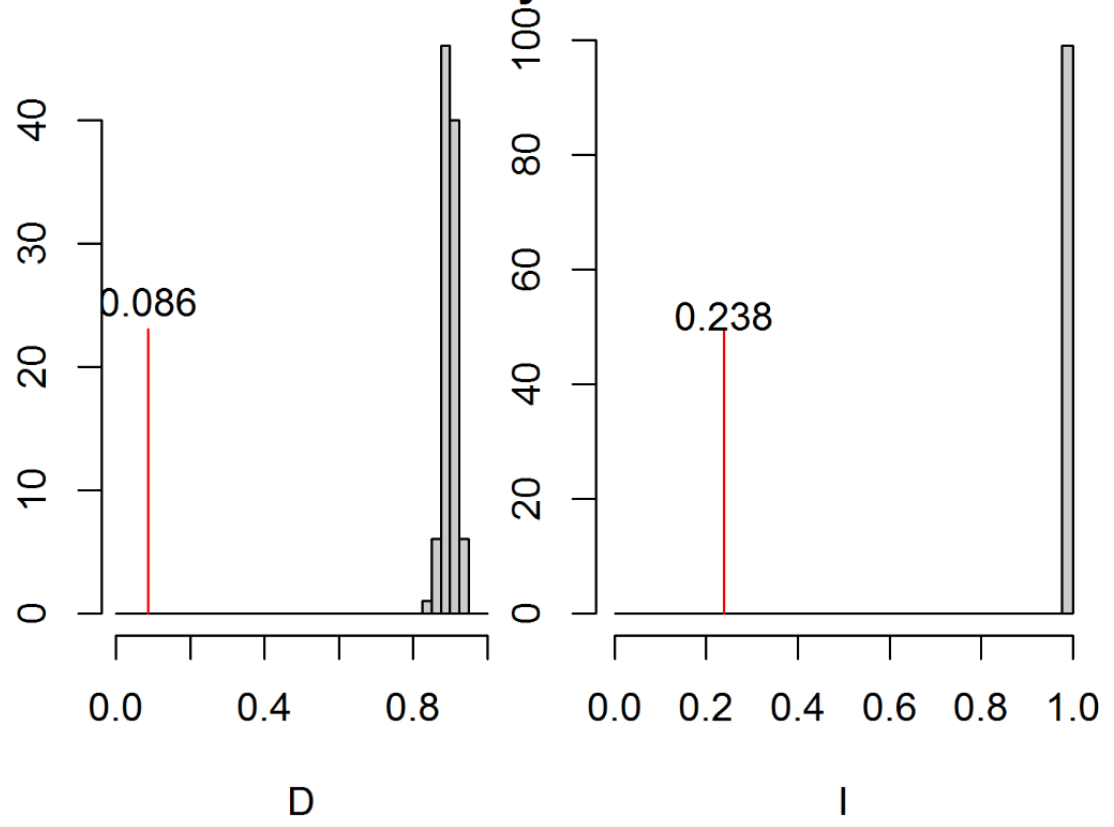

Figure 3: Identity Test showing niche overlap of the pair are outside the $95 \%$ confidence interval

\section{Discussion}

The niche difference has been clearly visible from the study. Four general factors are opined to be important causes of niche conservatism which are natural selection, gene flow, pleiotropy, and lack of variability (Wiens, 2004c; Wiens, 2004a). I believe, the lack of niche conservatism in this case could have been an interplay of some of these factors. The new ecological condition in Indus may not have been one that reduce their fitness or population growth. Otherwise, natural selection would favour traits that keep individual inside the niche if there was a cost of reduction of fitness or population growth (Holt and Gaines, 1992; Holt, 1996). Contemporary genetic exchange has been deemed unlikely since the populations are separated by several hundred kilometers of land at their closest point and the dispersal through brackish water has been deemed highly improbable (Braulik et al. , 2015). If there was a consideration of the dispersal abilities of species than it could radically change interpretations of niche similarity or difference (Peterson, 2011). A clear genetic differentiation between the two geographically isolated populations have been found through mtDNA study and there has been speculations that additional comparative investigations may allow recognition of these isolated populations as distinct taxa (Braulik et al. , 2015).

Likewise, non-conservatism can be achieved by any change of the three BAM (biotic, abiotic, movement) factors (Pearman et al. , 2008). The abiotic conditions includes the climate, physical aspects that impose physiological limits on species' ability to persist in an area. The biotic factors are the set of interactions with other species modifying the species' ability to maintain populations. Movement is the parts which are accessible to the species in some ecological sense. It is not clear as to the changes in which factors resulted in the non-conservatism in the present study but movement bears a special significance by initially separating the species through drainage capture and then creating of barrier through land and brackish water limiting their ability to interact.

While generally underutilized, SDM in combination of phylogenetics has already made contribution on species delimitation (Carstens et al. , 2013). In a study by Raxworthy et al. (2007) they used ecological niche modeling for studying species delimitation. The study elevated three subspecies to species rank using a combination of morphological, niche study and mitochondrial DNA. The additional comparative study 
as suggested by Braulik et al. (2015), should thus be conducted. An erroneous classification can lead to potentially inappropriate conservation management decisions for threatened species. The additional study could help to ascertain the taxonomic status of the South Asian Dolphins. This is fundamental for insights into the biology and evolution of species and effective conservation management (Huet al. , 2020). Carstens et al. (2013) recommend that supposition about species limits should use methods which is an integration across many data types and analyses. It is rather wise to fail to delimit species than to falsely delimit entities. The study clears the air on niche conservatism of the species and it is time to focus on the genetic evidence of the taxas.

\section{Conclusion}

The South Asian Dolphins show very little niche overlap but this article by no means ascertains the existence of two separate species of South Asian dolphins. But very little niche overlap were seen and their niches were not found to be equivalent. A lot of factors have been speculated on why the niche non-conservatism has been witnessed such as lack of contemporary genetic exchange. The study simply aids in the discussion that further efforts are needed to ascertain its taxonomic status. Correct species delimitation could have a lot of implications for the conservation of these Endangered taxas. Hence, I recommend further genetic study to affirm this claim.

\section{Statement of data achieving}

The supplementary data and OBIS-SEAMAP (http://seamap.env.duke.edu/) provides a complete reference of presence records.

\section{Acknowledgements (optional)}

I would like to thank Dr. Dan Warren for entertaining my queries on ResearchGate regarding the niche equivalency test. I would also like to thank Mr. Aashish Mishra for reviewing my manuscripts for formatting and grammatical errors. A special acknowledgement to the Majhi (indigenous fishing tribe) in Koshi River who's snatched catch from the protected area made a deep impact on me to study about Ganges River Dolphins.

\section{References}

Araujo, M., New, M. (2007) Ensemble forecasting of species distributions. Trends in Ecology \& Evolution . $22(1), 42-47$.

Araújo, M.B., Pearson, R.G., Thuiller, W., Erhard, M. (2005) Validation of species-climate impact models under climate change. Global Change Biology . 11 (9), 1504-1513.

Braulik, G.T., Barnett, R., Odon, V., Islas-Villanueva, V., Hoelzel, A.R., Graves, J.A. (2015) One Species or Two? Vicariance, Lineage Divergence and Low mtDNA Diversity in Geographically Isolated Populations of South Asian River Dolphin. Journal of Mammalian Evolution . 22 (1), 111-120.

Broennimann, O., Fitzpatrick, M.C., Pearman, P.B., Petitpierre, B., Pellissier, L., Yoccoz, N.G., Thuiller, W., Fortin, M.-J., Randin, C., Zimmermann, N.E., Graham, C.H., Guisan, A. (2012) Measuring ecological niche overlap from occurrence and spatial environmental data.Global Ecology and Biogeography . 21 (4), 481-497.

Carstens, B.C., Pelletier, T.A., Reid, N.M., Satler, J.D. (2013) How to fail at species delimitation. Molecular Ecology . 22 (17), 4369-4383.

Cola, V.D., Broennimann, O., Petitpierre, B., Breiner, F.T., D’Amen, M., Randin, C., Engler, R., Pottier, J., Pio, D., Dubuis, A., Pellissier, L., Mateo, R.G., Hordijk, W., Salamin, N., Guisan, A. (2017) ecospat: an R package to support spatial analyses and modeling of species niches and distributions. Ecography . 40 (6), $774-787$. 
Culumber, Z.W., Tobler, M. (2016) Ecological divergence and conservatism: spatiotemporal patterns of niche evolution in a genus of livebearing fishes (Poeciliidae: Xiphophorus). BMC Evolutionary Biology . 16 (1), 44.

Heibl, C., Calenge, C., Heibl, M.C. (2018) Package 'phyloclim'.

Hijmans, R.J., Phillips, S., Leathwick, J., Elith, J., Hijmans, M.R.J. (2017) Package ‘dismo'. Circles . 9 (1), $1-68$.

Holt, R.D. (1996) Demographic constraints in evolution: towards unifying the evolutionary theories of senescence and niche conservatism.Evolutionary Ecology . 10 (1), 1-11.

Holt, R.D., Gaines, M.S. (1992) Analysis of adaptation in heterogeneous landscapes: implications for the evolution of fundamental niches.Evolutionary Ecology . 6 (5), 433-447.

Hu, Y., Thapa, A., Fan, H., Ma, T., Wu, Q., Ma, S., Zhang, D., Wang, B., Li, M., Yan, L., Wei, F. (2020) Genomic evidence for two phylogenetic species and long-term population bottlenecks in red pandas.Science Advances . 6 (9), eaax5751.

Jnawali, S., Baral, H., Lee, S., Acharya, K., Upadhyay, G., Pandey, M., Griffiths, J. (2011) The status of Nepal mammals: the national red list series, department of national Parks and wildlife conservation kathmandu, Nepal. Preface by Simon M. Stuart Chair IUCN Species Survival Commission The Status of Nepal's Mammals: The National Red List Series . 4 .

Kasuya, T. (1972) Some informations on the growth of the Ganges dolphin with a comment on the Indus dolphin. Scientific Reports of the Whales Research Institute . 24, 87-108.

Kasuya, T., Haque, A. (1972) Some information on the distribution and seasonal movement of the Ganges dolphin. Scientific Reports of the Whales Research Institute . 24, 109-115.

Losos, J.B. (2008) Phylogenetic niche conservatism, phylogenetic signal and the relationship between phylogenetic relatedness and ecological similarity among species. Ecology Letters . 11 (10), 995-1003.

Miller, J. (2010) Species Distribution Modeling. Geography Compass . 4 (6), 490-509.

Moreno, P. (2003) Ganges and Indus dolphins. Grzimek's Animal Life Encyclopedia (Hutchins, M., Kleiman, D., Geist, V., Murphy, JB, Thoney, DA eds.). 15.

Muscarella, R., Galante, P.J., Soley-Guardia, M., Boria, R.A., Kass, J.M., Uriarte, M., Anderson, R.P. (2014) ENMeval: An R package for conducting spatially independent evaluations and estimating optimal model complexity for Maxent ecological niche models. Methods in Ecology and Evolution . 5 (11), 1198-1205.

Parmesan, C. (2006) Ecological and evolutionary responses to recent climate change. Annu. Rev. Ecol. Evol. Syst. . 37, 637-669.

Pearman, P.B., Guisan, A., Broennimann, O., Randin, C.F. (2008) Niche dynamics in space and time. Trends in Ecology \& Evolution .23 (3), 149-158.

Peterson, A.T. (2011) Ecological niche conservatism: a time-structured review of evidence: Ecological niche conservatism. Journal of Biogeography . 38 (5), 817-827.

Peterson, A.T., Soberón, J., Sánchez-Cordero, V. (1999) Conservatism of ecological niches in evolutionary time. Science .285 (5431), 1265-1267.

Pilleri, G., Gihr, M. (1971) Differences observed in the skulls of Platanista gangetica (Roxburgh, indi (Blyth, 1859). Investigations on Cetacea. In Investigations on Cetacea . pp. 13-21.

Pilleri, G., Marcuzzi, G., Pilleri, O. (1982) Speciation in the Platanistoidea, systematic, zoogeographical and ecological observations on recent species. Investigations on Cetacea . 14, 15-46. 
Price, T.D., Qvarnström, A., Irwin, D.E. (2003) The role of phenotypic plasticity in driving genetic evolution. Proceedings of the Royal Society of London. Series B: Biological Sciences . 270 (1523), 1433-1440.

R Core Team (2020) R: A language and environment for statistical computing. Vienna, Austria.: R Foundation for Statistical Computing.

Rato, C., Harris, D.J., Perera, A., Carvalho, S.B., Carretero, M.A., Rödder, D. (2015) A Combination of Divergence and Conservatism in the Niche Evolution of the Moorish Gecko, Tarentola mauritanica (Gekkota: Phyllodactylidae) S. Lötters, ed. PLOS ONE . 10 (5), e0127980.

Raxworthy, C.J., Ingram, C.M., Rabibisoa, N., Pearson, R.G. (2007) Applications of Ecological Niche Modeling for Species Delimitation: A Review and Empirical Evaluation Using Day Geckos (Phelsuma) from Madagascar. Systematic Biology . 56 (6), 907-923.

Reeves, R.R., Brownell Jr, R.L. (1989) Susu Platanista gangetica (Roxburgh, 1801) and Platanista minor (Owen, 1853). Handbook of marine mammals . 4, 69-99.

Rissler, L.J., Apodaca, J.J. (2007) Adding More Ecology into Species Delimitation: Ecological Niche Models and Phylogeography Help Define Cryptic Species in the Black Salamander (Aneides flavipunctatus).Systematic Biology . 56 (6), 924-942.

Rundle, H.D., Nosil, P. (2005a) Ecological speciation. Ecology Letters . 8 (3), 336-352.

Rundle, H.D., Nosil, P. (2005b) Ecological speciation. Ecology letters . 8 (3), 336-352.

Schoener, T.W. (1968) The Anolis lizards of Bimini: resource partitioning in a complex fauna. Ecology . 49 (4), 704-726.

Shepard, D.B., Burbrink, F.T. (2008) Lineage diversification and historical demography of a sky island salamander, Plethodon ouachitae, from the Interior Highlands. Molecular Ecology . 17 (24), 5315-5335.

Strubbe, D., Broennimann, O., Chiron, F., Matthysen, E. (2013) Niche conservatism in non-native birds in Europe: niche unfilling rather than niche expansion: Niche conservatism among non-native birds. Global Ecology and Biogeography . 22 (8), 962-970.

Thuiller, W., Lafourcade, B., Engler, R., Araújo, M.B. (2009) BIOMOD-a platform for ensemble forecasting of species distributions.Ecography . 32 (3), 369-373.

Wang, P., Liu, Yang, Liu, Yinong, Chang, Y., Wang, N., Zhang, Z. (2017) The role of niche divergence and geographic arrangement in the speciation of Eared Pheasants (Crossoptilon, Hodgson 1938).Molecular Phylogenetics and Evolution. 113, 1-8.

Warren, D.L., Glor, R.E., Turelli, M. (2010) ENMTools: a toolbox for comparative studies of environmental niche models. Ecography .

Warren, D.L., Glor, R.E., Turelli, M. (2008a) ENVIRONMENTAL NICHE EQUIVALENCY VERSUS CONSERVATISM: QUANTITATIVE APPROACHES TO NICHE EVOLUTION. Evolution . 62 (11), 2868-2883.

Warren, D.L., Glor, R.E., Turelli, M. (2008b) Environmental niche equivalency versus conservatism: quantitative approaches to niche evolution. Evolution: International Journal of Organic Evolution .62 (11), 28682883.

Webb, C.O., Ackerly, D.D., McPeek, M.A., Donoghue, M.J. (2002) Phylogenies and Community Ecology. Annual Review of Ecology and Systematics . 33 (1), 475-505.

Wellenreuther, M., Larson, K.W., Svensson, E.I. (2012) Climatic niche divergence or conservatism? Environmental niches and range limits in ecologically similar damselflies. Ecology .93 (6), 1353-1366.

Wiens, J.J. (2004a) Speciation and ecology revisited: phylogenetic niche conservatism and the origin of species. Evolution .58 (1), 193-197. 
Wiens, J.J. (2004b) What is speciation and how should we study it? The American Naturalist . 163 (6), $914-923$.

Wiens, J.J. (2004c) What is speciation and how should we study it? The American Naturalist . 163 (6), $914-923$.

Wiens, J.J., Graham, C.H. (2005) Niche Conservatism: Integrating Evolution, Ecology, and Conservation Biology. Annual Review of Ecology, Evolution, and Systematics . 36 (1), 519-539.

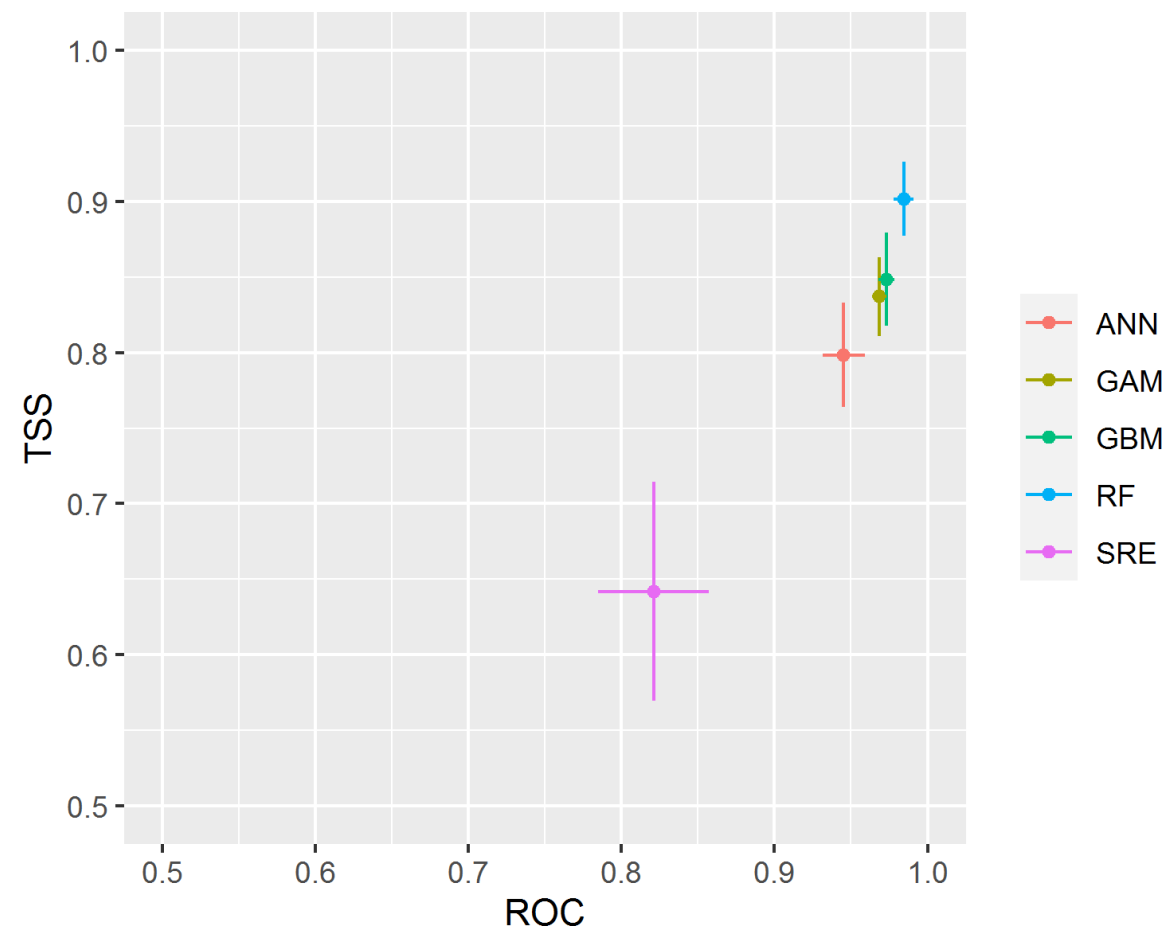



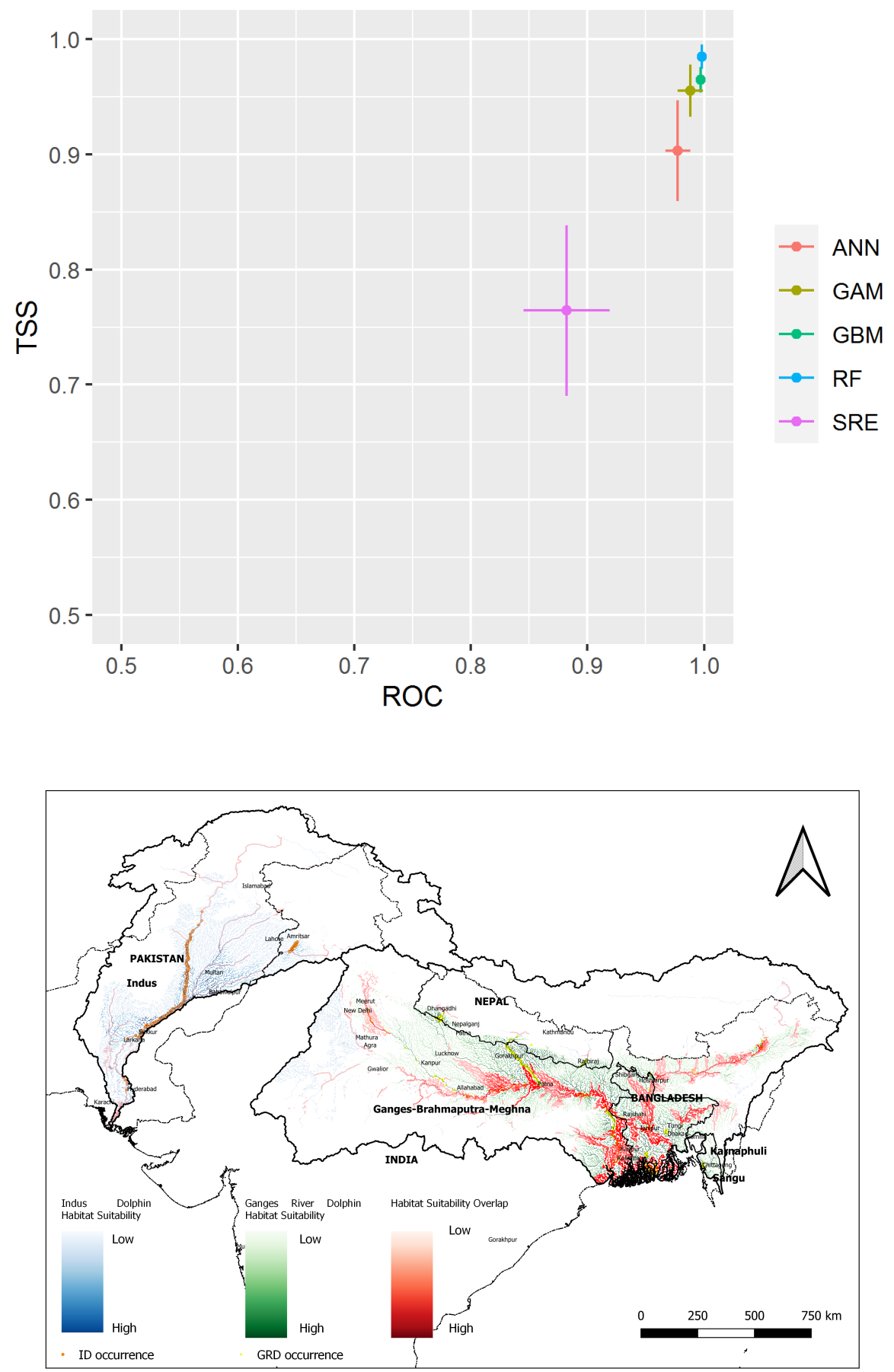
Niche identity test: GRD - ID

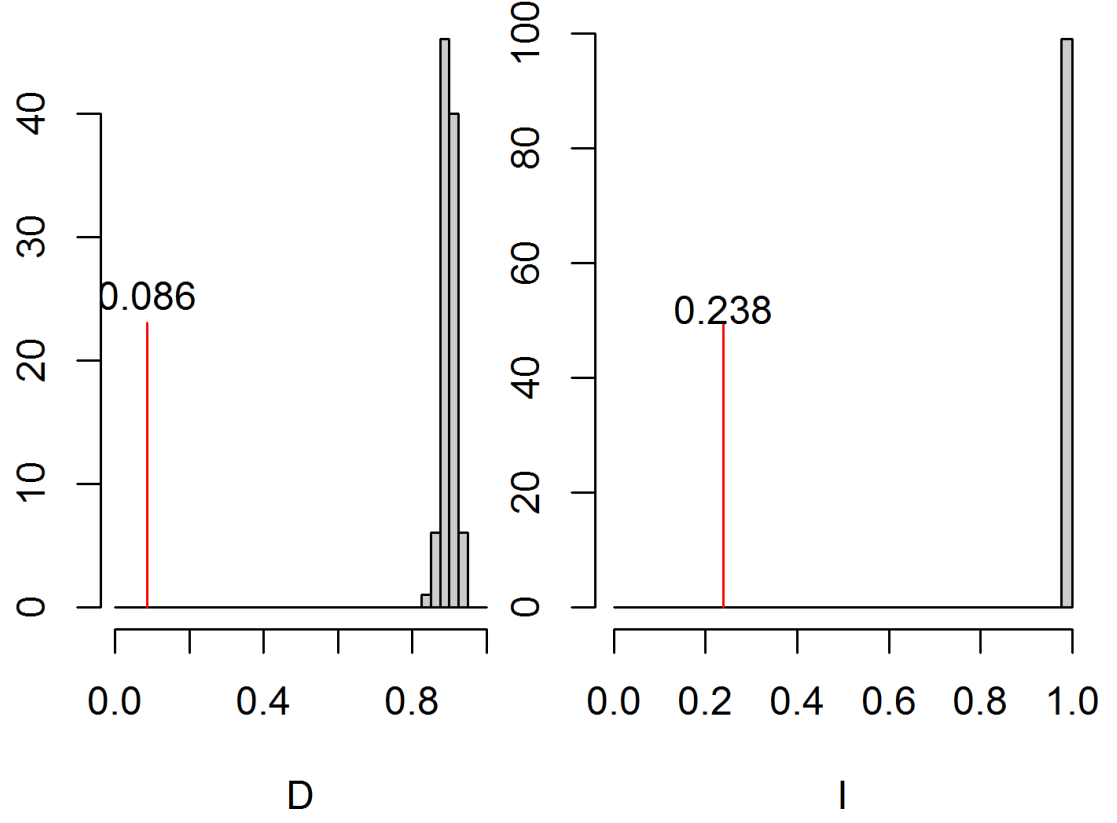

